\title{
РОЛЬ ЭКОНОМИЧЕСКОГО ФАКТОРА В ОТТОКЕ НАСЕЛЕНИЯ АКМОЛИНСКОЙ ОБЛАСТИ
}

\author{
И.Г. Плачинта \\ Кокщетауский Государственный Университет им. Ш. Уалиханова, Казахстан \\ Поступила в редакиию 18 июля 2018 г.
}

\begin{abstract}
Аннотация: В статье рассмотрено влияния экономического фактора на миграционную активность населения в условиях экономического кризиса посредством разработанной гравитационной модели. В качестве временного промежутка был взят период 2009-2013 годов, когда мировой кризис начал негативно отражаться на развитии экономики региона. Анализ влияния экономической эффективности на развитие миграции был осуществлен с помощью авторского метода гравитационного моделирования. В ходе анализа материалов за указанный период были выявлены центры миграции районного, регионального и республиканского уровней. Для изучения гравитационного влияния сопредельных населенных пунктов и экономических центров модели были составлены на территорию Северного Казахстана. По итогам исследования гравитационная модель отразила все основные центры оттока населения в области.
\end{abstract}

Ключевые слова: социально-экономическая эффективность, миграция, геоинформационные системы, гравитационное моделирование.

Abstract: The article considers the influence of the economic factor on the migration activity of the population in the conditions of the economic crisis through the developed gravitational model. As a time interval, the period of 2009-2013 was taken, when the global crisis began to have a negatively effect on the development of the region's economy. The analysis of the influence of economic efficiency on the development of migration was carried out using the author's method of gravitational modeling. During the analysis of materials for the specified period, migration centers of regional and republican levels were identified. To study the gravitational influence of adjacent settlements and economic centers, the models were compiled into the territory of Northern Kazakhstan. Based on the results of the study, the gravity model reflected all the main centers of population outflow in the region.

Key words: social and economic efficiency, migration, geographic information systems, gravity modelling.

Миграционные процессы представляются достаточно уникальным социальным явлением, природа которого многообразна в современном мире. Однако, если абстрагироваться от глобальной проблематики миграции, то в большинстве случаев она обусловлена экономическими факторами. Их влияние на поведение человека и стремление сменить место жительства не всегда можно оценить однозначно. С одной стороны, каждый человек выбирает индивидуальные причины для переезда, лучшие качества жизни в новом регионе. С другой стороны, есть и общественные оценки и восприятие каждого региона с позиции благополучия. Географию экономической «благополучности» peгионов можно сравнить с таким пространством, в каждой точке которого присутствует набор харак-

(с) Плачинта И. Г., 2019 теристик, указывающих на потенциальный уровень качества жизни [16]. Исходя из этого, можно прийти к выводу, что современные территориальные общественные системы уже представляют собой социально-экономическое пространство, в пределах которого формируются «экономические поля», отражающие как индивидуальные показатели, так и обобщенные. В развивающихся странах разный уровень экономического развития региональных территориальных общественных систем служит подобием физического понятия разности потенциалов, из-за которого могут формироваться миграционные потоки населения. Усилением разности потенциалов в «экономическом поле» могут послужить кризисные явления в экономике отдельных частей региона. К таковым можно отнести районы с аграрной экономикой. Раз- 


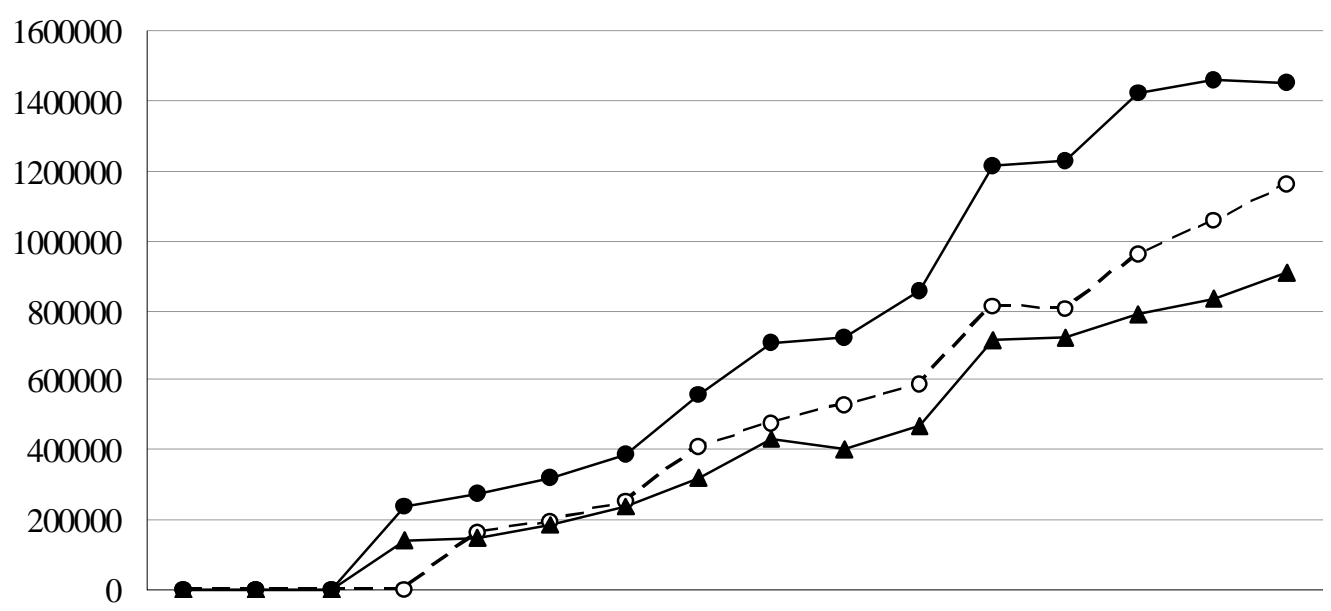

2000200120022003200420052006200720082009201020112012201320142015

- -о- - Акмолинская область

$\longrightarrow$ Северо-Казахстанская область

$\longrightarrow$ Костанайская область

Puc. 1. Динамика валового регионального продукта (ВРП) регионов Северного Казахстана (млн. тенге)

ность потенциалов «экономического поля» может являться основой для возникновения миграции, в том числе как ответная реакция населения на складывающуюся экономическую действительность в местах проживания. Выражение миграции через понятие разности потенциалов дает возможность рассмотреть ее посредством гравитационной модели. Каждая точка такой модели, обладая собственным потенциалом, складывающимся из совокупности социально-экономических показателей, формирует «экономическое поле» с более или менее благополучными районами относительно уровня жизни. Таким образом, данный тезис подводит к идее о гравитационном происхождении современных миграционных потоков на уровне отдельной страны и ее регионов.

\section{Основополагающие данные для исследования}

Акмолинская область - один из регионов Республики Казахстан с агро-индустриальной направленностью экономики. В Северном Казахстане Акмолинская область по экономическим показателям (рис. 1) уступает индустриальным регионам - Павлодарской области (в 1,5 раза) и Костанайской (в 1,2 раза), а также городу Астана (в 4 раза).

Общий рост экономики не создавал благоприятных условий для миграционного притока. Акмолинская область длительное время была регионом-донором как для стран ближнего зарубежья (до 2000-2005 годов), так и для соседних индустриальных районов. Особенный интерес представляет период с 2008 года, когда разразился мировой экономический кризис. В рассматриваемых регионах Северного Казахстана он вызвал нестабильную динамику валового регионального продукта. В индустриальных регионах, в отличие от агро-индустриальных, наблюдалась общая положительная тенденция. Наибольшая разница в показателях ВРП фиксировалась уже к середине данного периода. Подобная экономическая ситуация дает возможность провести анализ влияния экономического фактора в условиях экономического кризиса на миграцию в период 2009-2013 годов.

В Акмолинской области еще с 90-х гг. прошлого века наблюдается рост оттока населения. Общие закономерности развития миграционных процессов, частично отраженные на рисунке 2, следующие: 1) снижение миграционного оборота; 2) переориентация потоков с внешней миграции на межрегиональную; 3 ) цикличный ход миграционного оттока.

В рассматриваемый период наиболее кризисным, в отношении миграционного оттока, представляется 2009 году (рис. 3). Главным направлением для эмиграции населения области стали более благополучные в экономическом плане регионы страны, среди которых выделяются Атырауская область и Астана.

На фоне явно негативной картины миграции следует выделить наличие внутриобластных центров миграции, которые стали опорными точками для центростремительных движений населения. В качестве таковых, по данным 2009 года, можно выделить города Кокшетау и Степногорск, а также Целиноградский (пригородная зона столицы), 
Роль экономического фактора в оттоке населения Акмолинской области

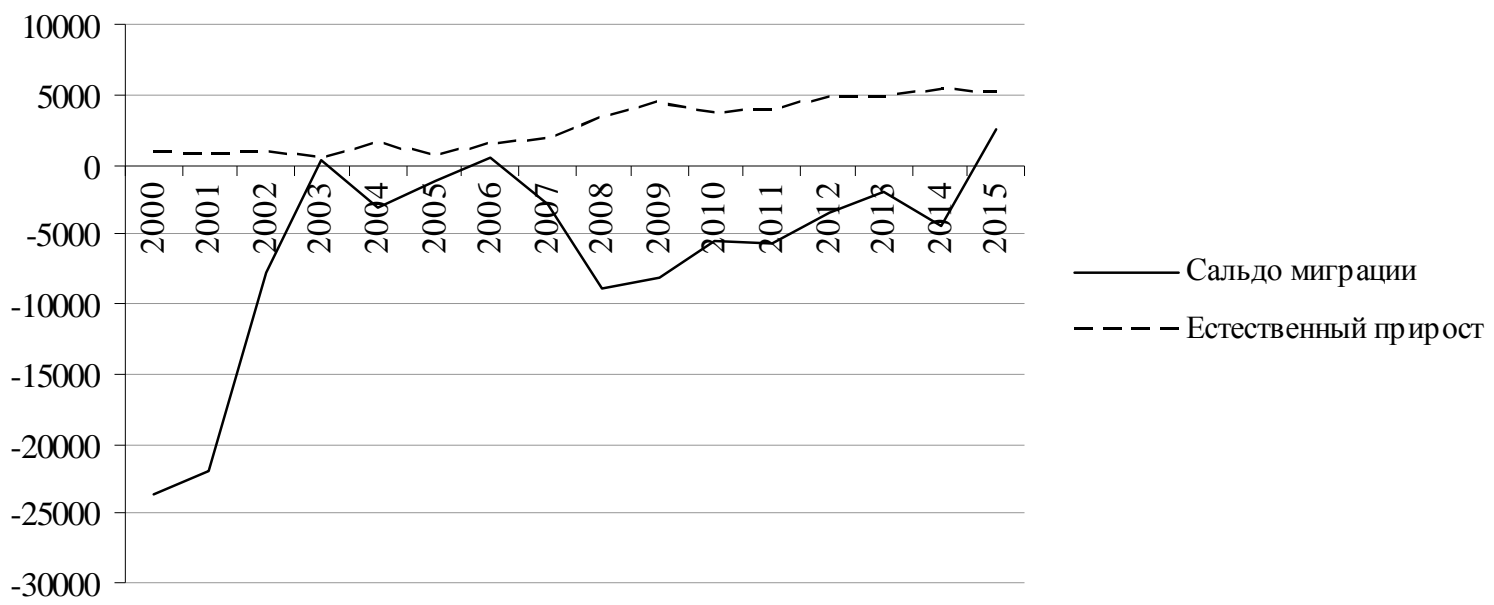

Puc. 2. Основные показатели миграции населения Акмолинской области в 2000-2015 годах

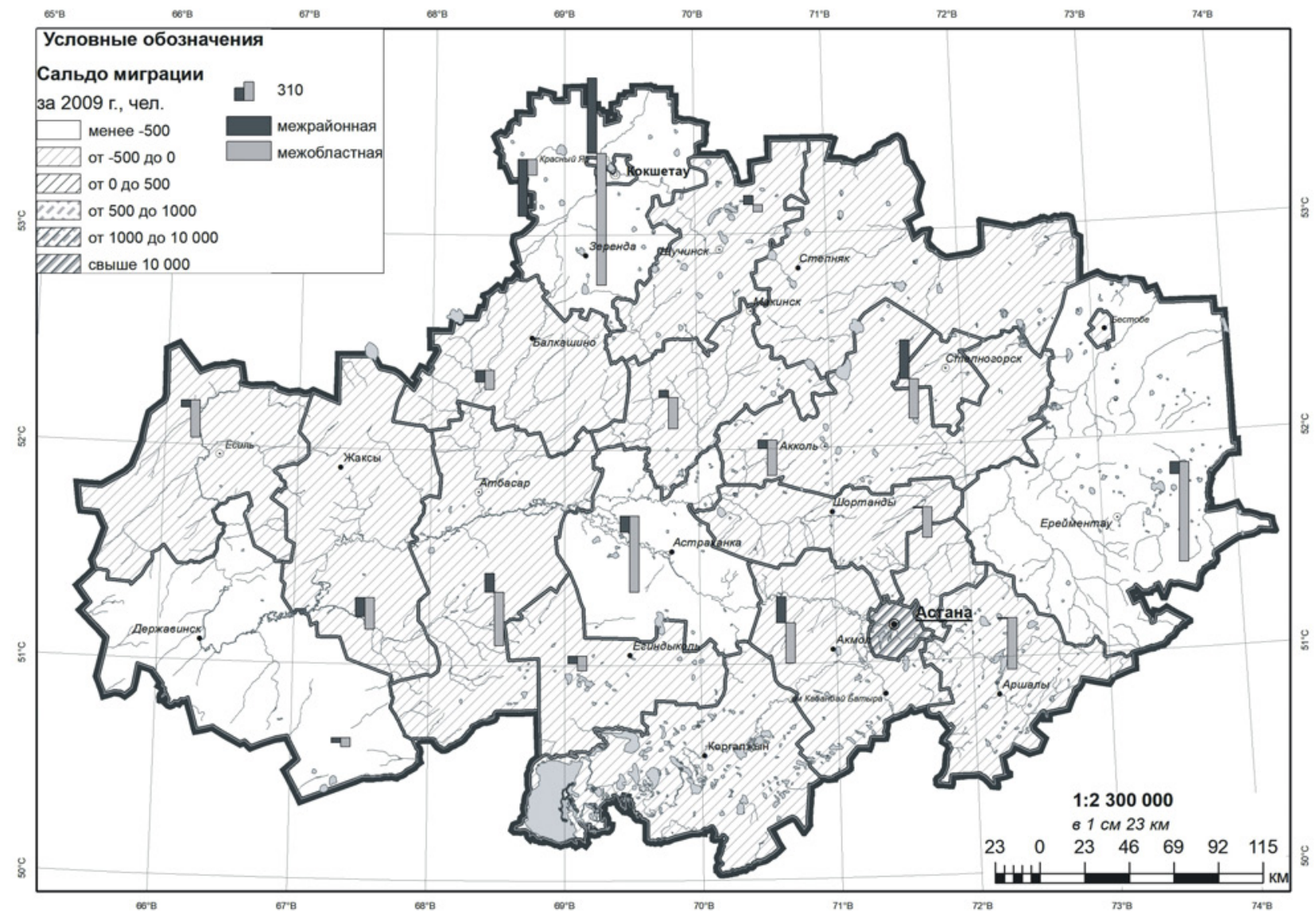

Puc. 3. Сальдо миграции в разрезе районов Акмолинской области

Бурабайский (город Щучинск и п. Бурабай) и Буландинский (город Макинск) районы. Указанные районы имеют развитый промышленный (в том числе агропромышленный) комплекс, благодаря чему сохранили благоприятные социально-экономические условия для проживания населения по сравнению с соседними аграрными районами.

Неблагоприятная миграционная картина сохранялась в течение всего периода до 2013 года. Од- нако, центростремительные движения усиливались, расширяя географический охват влияния каждого местного центра миграции. Так, по статистическим данным 2009-2013 годов, значения сальдо миграции стали положительными лишь в двух районах (рис. 4) - Бурабайском и Целиноградском. В первом случае благодаря инвестициям в рекреационную зону, а во втором - благодаря экономическому влиянию близости столицы. Другой 


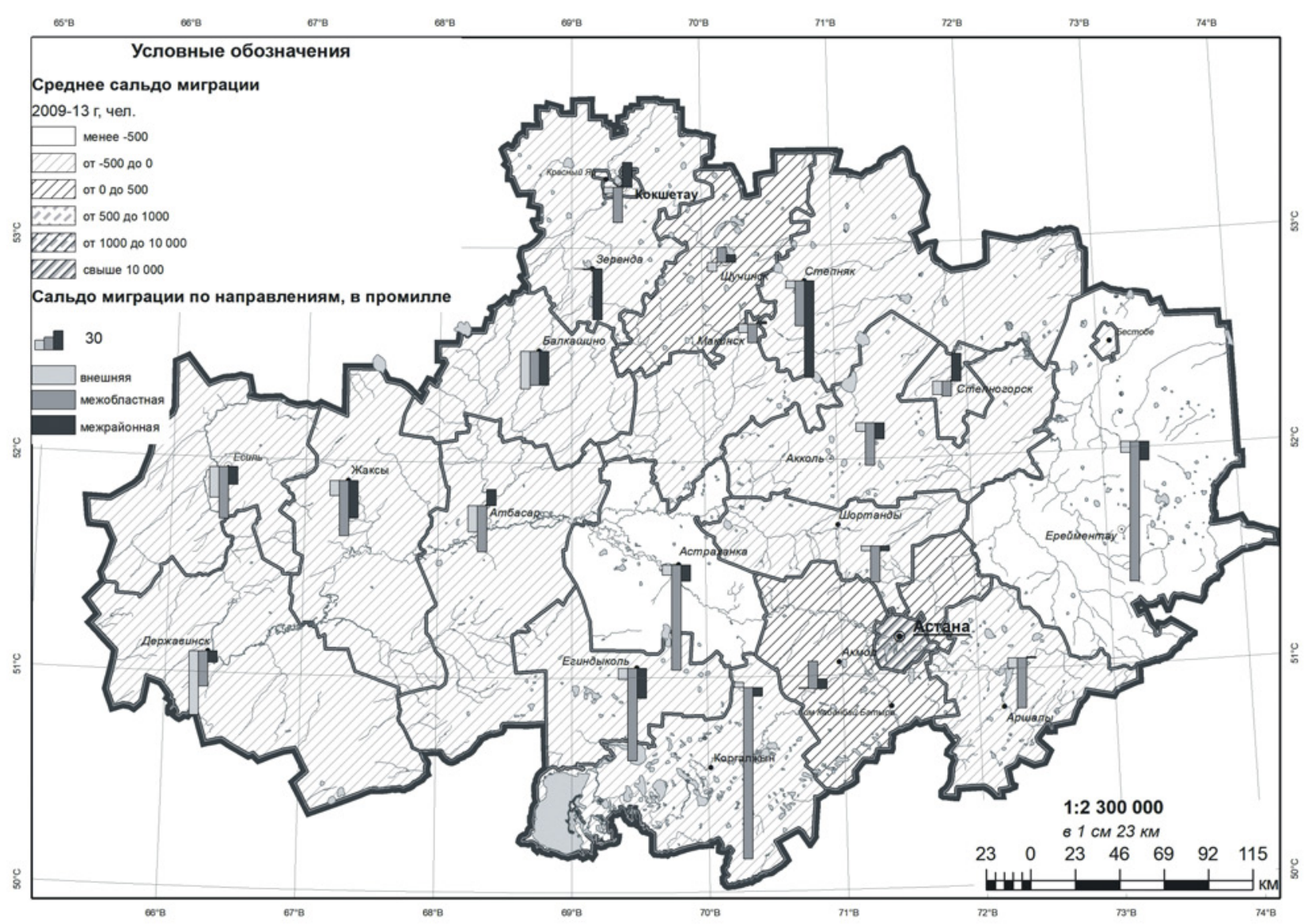

Puс. 4. Средние значения сальдо миграции 2009-2013 годах

фактор - низкая роль внешнего направления миграции, вся основная миграционная нагрузка приходится на межрегиональное и внутриобластное направления. Этот факт указывает на экономическую составляющую миграции.

К 2013 году Целиноградский район трансформировался из местного центра миграции в региональный. Более того, уже на современном этапе он позиционируется как центр миграции республиканского уровня. Сальдо миграции в среднем за год по межрегиональному направлению составило $22 \%$, а по внутриобластному - 7,8\%o. Положительный баланс межрегиональной миграции объясняется также дешевизной стоимости земли для строительства. И уже в тот период, ввиду развития транспортной инфраструктуры в пригородной зоне столицы, фиксировались отдельные явления субурбанизации.

Бурабайский район и город Щучинск трансформировались к 2013 году до уровня центров миграции областного значения. Этот статус фактически остается до сих пор. Значения сальдо миграции с межрегионального и внутриобластного направлений оценивается по 12,4\%о и 5,9\%о в год, соответственно.

Остальные крупные города и экономические центры можно отнести разве только к центрам миграции районного уровня. Для них характерны отрицательные значения сальдо миграции по внешнему и межрегиональному направлению, а отток компенсируется внутриобластной иммиграцией. Выделим подобные центры в соответствии со средними значениями сальдо миграции по внутриобластному направлению за 2009-2013 годы: город Степногорск - 21,9\%о в год, город Кокшетау - 19,3\%o, Аршалынский район - 0,7\%o, город Атбасар - $13 \%$, город Макинск - 2\%о. В Аршалынском районе экономический интерес для мигрантов представляет пригородная зона столицы до села Жибек Жолы (часовая зона доступности) и только потом районный центр - село Аршалы.

Следует особо выделить кризисные районы, где сальдо миграции по всем направлениям был отрицательным. Это, в первую очередь, районы дальней периферии - бывшие территории Тургайской области, ныне расположенные в юго-запад- 
ной части Акмолинской области, а также аграрные районы центральной полосы. В некоторых районах фиксировались значительные отрицательные значения сальдо миграции. Так, в Енбекшильдерском, Коргалжынском, Астраханском районах значения сальдо миграции только по межрегиональному направлению изменялось в пределах от $-83 \%$ до $-137 \%$ в год. Интересен тот факт, что естественный прирост в данных районах имеет положительную динамику. Следовательно данные районы стали неофициальными донорами трудовых ресурсов. Более того, выявляется связь в движении населения между соседними районами. Так, можно выделить векторы миграции: Енбекшильдерский район - город Щучинск, Ерейментауский район - Целиноградский (пригородная зона).

Таким образом, можно отметить, что в 20092013 годах и экономическая, и миграционная ситуации в Акмолинской области демонстрировали отрицательные явления. Остается найти связь между данными явлениями через оценку влияния экономического фактора.

Оценку экономического фактора предлагается рассмотреть через понятие о географии экономического «поля». В этом случае необходимо понимать, что экономические показатели представляют собой результат использования имеющихся природных, производственных, демографических и финансовых ресурсов. В зарубежной экономике существует понятие, введенное экономистом В. Парето, которое очень хорошо описывает данный результат - экономическая эффективность [8, C. 5]. Данное понятие использовано в качестве основы для дальнейших расчетов.

\section{Обзор ранее выполненных исследований}

В рамках данного исследования были привлечены публикации по демографии региона, экономической эффективности и критериальному анализу экономических показателей. Работ по демографическому анализу Акмолинской области и Северного Казахстана оказалось немного. Среди них проанализированы работы Третьяковой С.Н. [9], Садовской Ю.В. [13, 14], Притворовой Т. П. [11], Маккева И.Ю. [5], а также отчеты по региональным программам [2]. В основу работ по статистике положены статистические сборники по Акмолинской области $[3,4]$.

На основании проведенного исследования научно-теоретических подходов к определению сущности понятия «экономическая эффективность» были использованы подходы, изложенные в работах Растворцевой С. Н. [12] и Белоусова Р. А. [1].
Под экономической эффективностью ими рассматривается состояние социально-экономической системы, изучение которой приемлемо выполнять посредством критериального анализа. Данные критерии были раскрыты в работах Нестерова А. А., выделившего базовые и дополнительные факторы [7]. Исследования в сфере гравитационных моделей размещения населения рассматривались на теоретическом уровне в работах Матлина И. С. [6] и на практическом уровне с выведением алгоритма ГИС-анализа в трудах Фалейчик Л. М. и Горина К. В. [15]. Анализ названных исследований позволил построить последовательность в изучении влияния экономической эффективности развития региона на миграцию посредством геоинформационных средств.

\section{Методы исследования}

Для изучения влияния экономической эффективности на миграцию был разработан метод гравитационного моделирования, основанный на использовании приемов шкалирования и критериального оценивания. Этапы реализации данного метода следующие: 1) определение социально-экономических показателей для оценки экономической эффективности: уровень заработных плат, инвестиций, промышленного производства, строительства; 2) определение сети населенных пунктов, имеющих наибольшую экономическую эффективность - города, районные центры, промышленные поселки, периферийные села и аулы с нулевой эффективностью; 3) фиксирование демографического веса каждого населенного пункта посредством среднегодового значения за 20092013 годы; 4) использование приема шкалирования.

Экономические показатели разнородны по качественным и метрическим значениям. Сложно оценивать их влияние на миграцию, используя только абсолютные значения. Необходимо создать критерии для оценки роли экономических показателей и достичь возможности их суммации. Для этого был разработан прием шкалирования, где значения шкалы - критериальные значения (баллы), соответствующие уровням наиболее развитого экономического региона (или центра), средних значений по стране и по объекту изучения (экономический район или область). При суммировании баллов получаем значение гравитационного индекca. В таблице приведен пример дифференциации значений условного показателя согласно приему шкалирования. В первом столбце приведены пороговые баллы, разграничивающие основные уровни экономических показателей. Во втором 
Пример разработки приема шкалирования (составлено автором)

\begin{tabular}{|c|c|c|c|}
\hline $\begin{array}{c}\text { Основные значения } \\
\text { шкалы (баллы) }\end{array}$ & $\begin{array}{c}\text { Промежуточные } \\
\text { значения (баллы) }\end{array}$ & Уровень показателя & $\begin{array}{c}\text { Условный } \\
\text { экономический } \\
\text { показатель }\end{array}$ \\
\hline 0 & - & - & 0 \\
\hline- & 0,$33 ; 0,66$ & - & $33000 ; 66000$ \\
\hline 1 & - & среднеобластной & 100000 \\
\hline- & 1,5 & - & 150000 \\
\hline 2 & - & средний по стране & 300000 \\
\hline- & 2,$33 ; 2,66$ & - & $333000 ; 666000$ \\
\hline 3 & - & максимальный по стране & 10000000 \\
\hline
\end{tabular}

указаны промежуточные значения для выявления места районов по уровню их экономической эффективности. Интервалы промежуточных значений могут быть кратны трем $(0,33 ; 0,66)$ или пяти $(0,5)$. В четвертом столбце значения соответствующие баллам «1», «2», «3»- вычисляются согласно данным статистики. Конвертации в балльной системе подвергается «демографический вес» опорных точек, по которым будет вычисляться гравитационный индекс. В качестве опорных значений в шкале были приняты значения - 10 тыс., 100 тыс. и 1 млн. жителей.

Пространственно-математическая обработка данных начинается с определения пространственных опорных точек отсчета обобщенных показателей. В качестве таких точек предлагаются административные центры и города, так как именно они в большинстве случаев являются носителями экономического потенциала определенного района. Для каждой опорной точки высчитывается гравитационный индекс. Заключительным является расчет гравитационной модели и ее картографическая реализация. Расчет гравитационной модели предлагается проводить по следующей формуле (1):

$$
V_{j}=P_{j}+\sum_{i=1}^{n-1} V_{j}^{i}=P_{j}+\sum_{i=1}^{n-1} \frac{P_{i}}{r_{i j}},
$$

где $V$ - гравитационный потенциал, $P$ - значение гравитационного индекса для $j$ - искомого населенного пункта относительно совокупности остальных пунктов $i$, расположенных на расстоянии $r$.

Картографическая реализация гравитационной модели была реализована посредством ГИС «ArcGIS» через инструменты интерполяции значений и создания TIN-поверхности [10].

\section{Результаты исследования и их обсуждение}

Исследование влияния экономической эффективности на миграцию было реализовано для
Акмолинской области посредством разработки гравитационной модели натерриториюэкономического района Северного Казахстана. Разработка модели на столь обширную область необходима с целью изучения гравитационного влияния (фактически экономических показателей) соседних крупных населенных пунктов.

Гравитационная модель отражает привлекательность опорных точек для миграции с позиции экономических показателей. При интерпретации данных с модели необходимо обратить внимание, что значения «4-5» и «9-10» являются пороговыми. В первом случае онисоответствуют среднерегиональным, а во втором - среднереспубликанским показателям. Соответственно, опорная точка, имеющая данные значения или более высокие, может рассматриваться как потенциальный центр миграции по региону или в стране. Значения «1» и «2-3» можно рассматривать как признак центра миграции внутрирайонного и районного значений соответственно.

По составленным гравитационным моделям на входной (рис. 5) и выходной (рис. 6) год фиксируется усиление гравитационного поля в крупных промышленных центрах Северного Казахстана Астана, Павлодар, Экибастуз, Рудный, Костанай. В Акмолинской области гравитационное поле населенных пунктов демонстрирует незначительное ослабление, и только близ столицы отмечается его усиление.

В Акмолинской области наибольшие значения гравитационного потенциала, не считая пригородной зоны Астаны, достигают всего 2-2,4 в городе Кокшетау, что ниже среднерегионального порога и может соответствовать центру миграции районного значения. Однако четко прослеживаются локальные центры миграции местного значения - города Щучинск, Макинск, Степногорск, Атбасар, Есиль, Акколь. При этом соседние населенные 


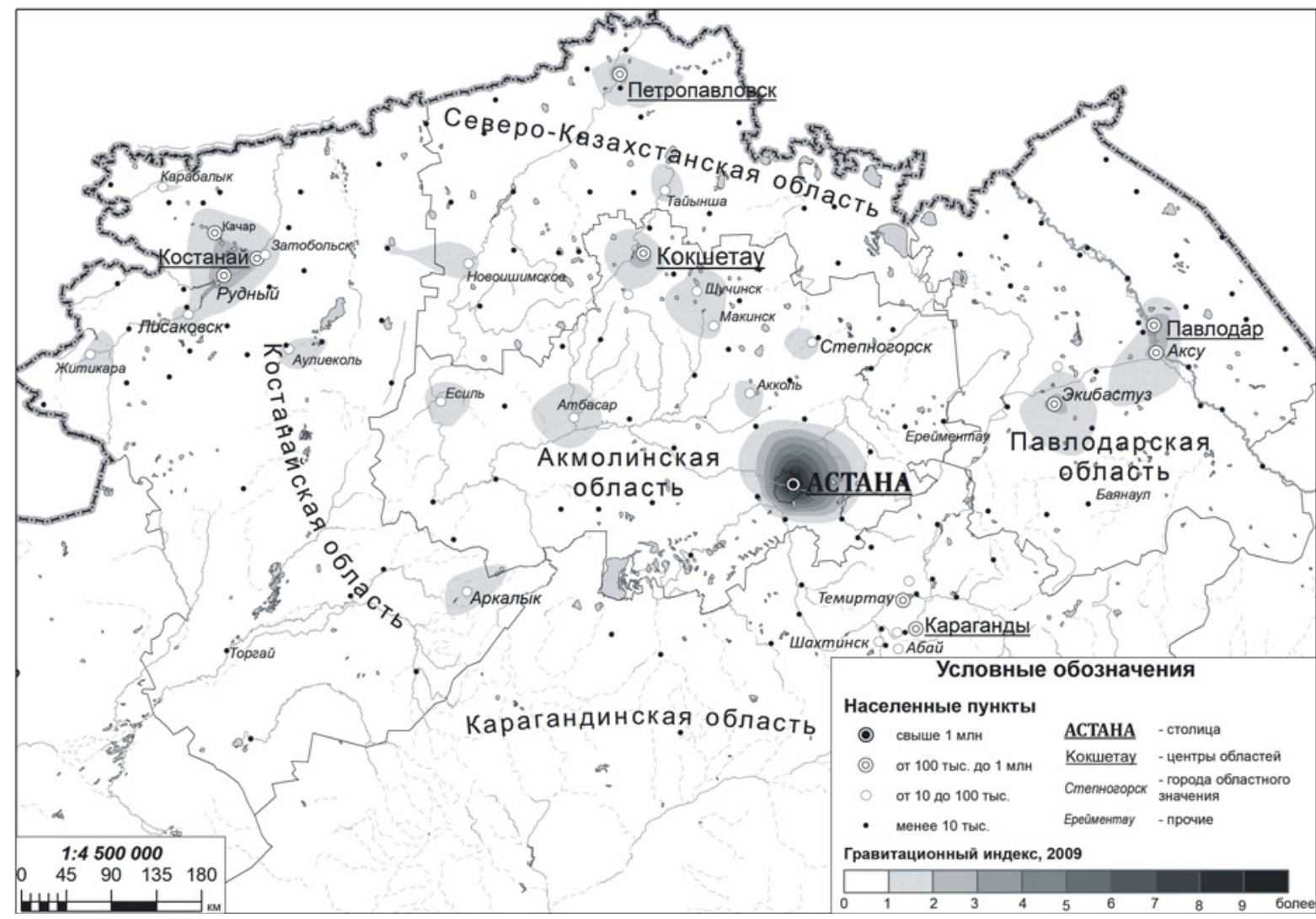

Рис. 5. Гравитационная модель за 2009 год

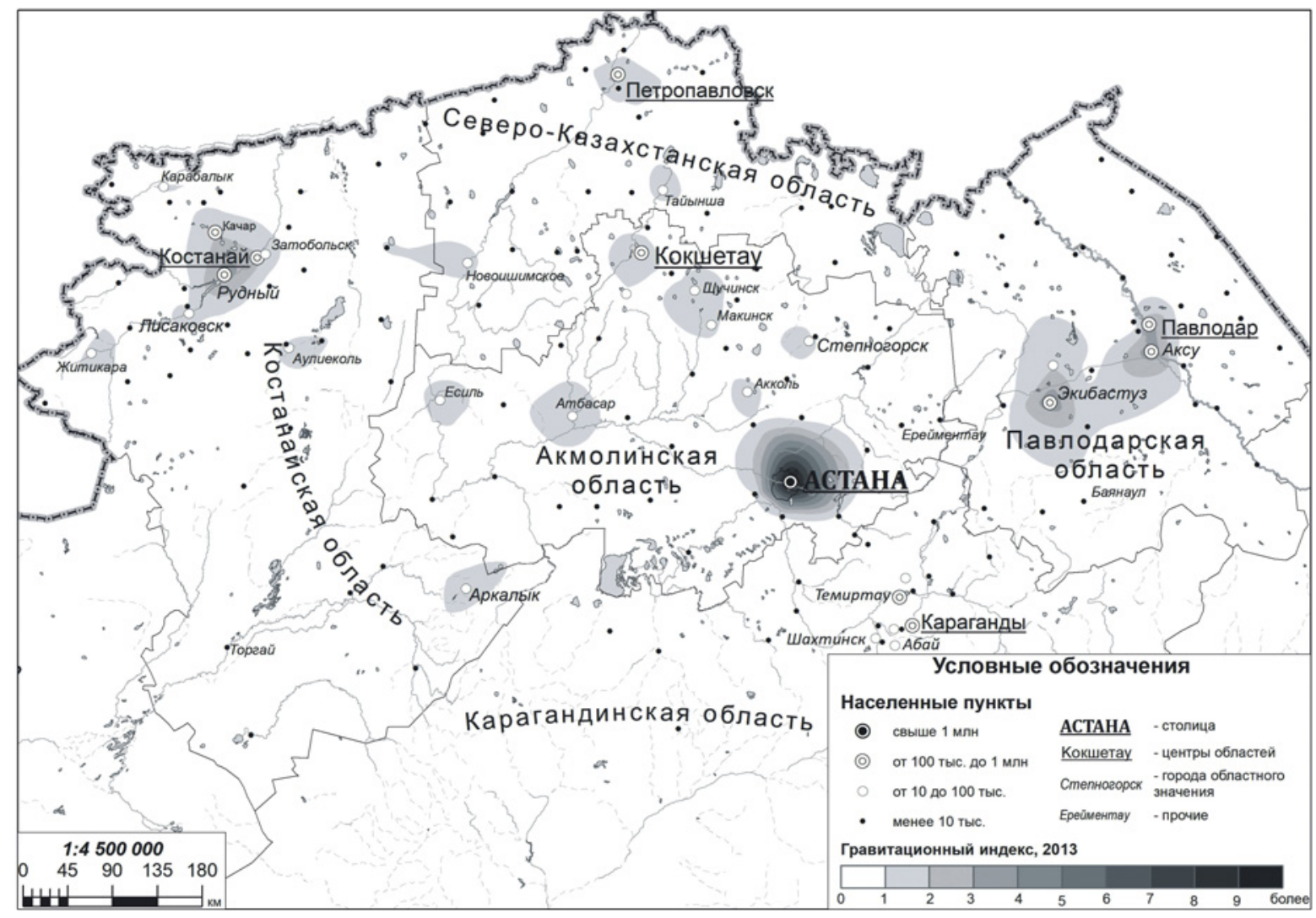

Рис. 6. Гравитационная модель за 2013 год 
пункты других регионов Северного Казахстана практически не влияют на распределение гравитационных полей. Самый главный центр миграции в области с возрастающим гравитационным потенциалом к 2013 году - 7-8 баллов зафиксирован в Целиноградском районе (с. Акмол). Можно утверждать, что социально-экономические показатели и бурный демографический рост в данном районе имеют определенную прямую зависимость. Рост и расширение гравитационного поля по данному району можно связать с увеличением поля гравитационного потенциала столицы (с 10,1 до $10,8)$. Столица действительно уже в 2009-2013 годах стала одним из национальных центров миграции, и, более того, ряд населенных пунктов вокруг столицы получил импульс в демографическом развитии к 2009 году на 10-20\% в год по численности населения.

Сопоставляя данные рисунка 1 и материалы гравитационных моделей, находим действительное ослабление гравитационных полей вокруг экономических центров агроиндустриальных регионов. В данном случае имеется в виду не только Акмолинская, но и Северо-Казахстанская область. На моделях рисунка 5 и 6 по размерам и плотности цвета областных центров Кокшетау и Петропавловск заметно изменение в количественных и качественных характеристиках ареалов. Этот факт указывает на то, что период 2009-2013 годов оказался кризисным не только в экономике Акмолинской области и подобных ей агроиндустриальных регионов Северного Казахстана, но и сказался на экономической привлекательности отдельных экономических центров для миграции. Валовые и средние показатели сальдо миграции указывают на наличие преобладающего оттока населения по большинству районов. Единственным фактором, в какой-то степени компенсирующим отток населения из области, является близость к столице, благодаря которому развивается пригородная зона в пределах Целиноградского района, а затем привлекаются инвестиции на открытие новых объектов инфраструктуры и легкой промышленности.

\section{Заключение}

Данная статья является второй, в которой метод гравитационного моделирования используется для выявление экономической составляющей в миграции населения. Если в первой статье задачей было изучение первичных результатов по материалам статистических данных 2016 года и тогда выявлено наличие связи между экономически- ми показателями и миграционной картиной [10], то в текущем исследовании акцент сделан на использовании ретроспективного подхода в изучении экономического фактора, расширении географического охвата модели, изучении гравитационного влияния крупных населенных пунктов соседних регионов. По результатам исследования были сделаны следующие выводы.

1. За указанный период фактически столица являлась главным центром притяжения для населения области, чему способствовало активное экономическое развитие Астаны и непосредственная географическая близость к ней.

2. В ходе экономического развития Акмолинской области и столицы формировались новые центры миграции: Целиноградский, Бурабайский и Буландинский районы, а также города Кокшетау и Степногорск. В гравитационной модели отражены данные центры притяжения населения. Более того, указаны дополнительные населенные пункты, которые являются центрами внутрирайонного миграции. Это относится к городам Есиль и Акколь.

3. Выделенные центры миграции имели разную динамику развития: Целиноградский район к 2013 году стал региональным центром притяжения населения благодаря развитию пригородной зоны столицы, остальные центры в основном сохранили районный статус.

4. Основную часть гравитационного индекса практически для всех населенных пунктов области составила их собственная демографическая «масса». Сверх ее фиксировались значения только по городу Кокшетау на 2009 год за счет показателя объемов инвестиций $(0,3)$. В данном случае фиксируется невысокий относительный уровень экономической эффективности по области, сопряженный со слабыми центростремительными и преобладанием центробежного движения населения.

5. В условиях низкого собственного гравитационного потенциала появляется возможность изучить роль наведенного потенциала от ближайших экономических центров, главным из которых является Астана. Гравитационный индекс по Целиноградскому району отразил влияние экономического фактора за счет близости столицы. Гравитационный индекс, высчитанный для районного центра, составил всего 0,5 (за счет демографической «массы»). Однако при расчете гравитационного потенциала по формуле (1), в которой учитывается собственный и наведенный гравитационный потенциал, значения превысили 1,0. Это является наибольшим значением наведенного гравитаци- 
онного потенциала. К примеру, для города Кокшетау значения изменяются в пределах $0,3-0,31$, в городе Павлодар - 0,38-0,4, в промышленном поселке Кашар (месторождение железных руд в Костанайской области) - 0,35. Аналогичная картина (наведенный потенциал 0,4-0,45) складывается в селе Кабанбай батыра (Целиноградский район), селе Шортанды (Шортандинский район), селе Аршалы. Все данные населенные пункты расположены на расстоянии 30-60 км. В данном случае максимальный наведенный потенциал в совокупности с положительным сальдо миграции (2010-2013 гг.) по Целиноградскому району демонстрируют прямую положительную связь.

6. Расширение гравитационной модели позволило получить общую картину на окраинах рассматриваемого региона. Однако важен и другой географический аспект, который необходимо рассмотреть в последующих работах - Карагандинская агломерация, которая по показателям может находиться на уровне среднереспубликанских и оказывает влияние на территории Аршалынского и Коргалжынского районов. В последнем случае можно гипотетически найти дополнительный источник большого оттока населения в соседние регионы. Единственным препятствием является методологический вопрос, который возникает в связи с расширением территории изучения и выходом за пределы одного экономического района.

\section{СПИСОК ЛИТЕРАТУРЫ}

1. Белоусов Р. А. Общий и специальный менеджмент / Р. А. Белоусов, А. Л. Гапоненко. - Москва : Издательство Российской академии государственной службы, 2001. - 568 с.

2. Габдуллина А. Р. Государственное регулирование миграции сельских жителей (проблемы социально-экономического развития сельских территорий Акмолинской области) / А. Р. Габдуллина // Экономика сельского хозяйства. Реферативный журнал - 2006. - № 1. C. 161 .

3. Демографический ежегодник Акмолинской области 2007-2011 : Статистический сборник. - Кокшетау : Управление статистики Акмолинской области, 2012. - 119 c.

4. Демографический ежегодник Акмолинской области 2013 : Статистический сборник. - Кокшетау : Управление статистики Акмолинской области, 2014. $-119 \mathrm{c}$.

5. Маккев И. Ю. Миграция русскоязычного населения из Казахстана / И. Ю. Маккев // Социологические исследования. - 1999. - № 11. - С. 62-67.

6. Матлин И. С. Моделирование размещения населения / И. С. Матлин. - Москва : Наука, 1975. - 153 с.
7. Нестеров А. А. Обзор факторов, определяющих межрегиональную и региональную миграцию в Российскую Федерацию / А. А. Нестеров // Российское предпринимательство. - 2015. - № 5-2. - С. 183-187.

8. Парето В. Компендиум по общей социологии / В. Парето; пер. с итал. А. А. Зотова. - Москва : Высшая школа экономики, 2008. - 511 с.

9. Перспективы роста населения в Республике Казахстан до 2021 года / С. Н. Третьякова [и др.] // Вестник Казахского национального медицинского университета. - 2015. - № 1. - С. 494-496.

10. Плачинта И. Г. Разработка приема анализа влияния экономического фактора на миграцию (на примере Акмолинской области) / И. Г. Плачинта // Наука. Инновации. Технологии. - 2018. - № 1. - С. 131-143.

11. Притворова Т. П. Тенденции демографического поведения населения Акмолинской области / Т. П. Притворова, М. Ш. Такамбаев // Вестник Карагандинского государственного университета. - 2010. - № 2. - C. 21-27.

12. Растворцева С. Н. Социально-экономическая эффективность регионального развития / С. Н. Растворцева. - Москва : Экон-Информ, 2011. - 131 с.

13. Садовская Ю. В. Миграция в Казахстане на рубеже XXI века : основные тенденции и перспективы / Ю. В. Садовская. - Алматы : Fалым, 2001. - С. 108-124.

14. Садовская Ю. В. Трудовая миграция как средство адаптации к экономическому кризису в Казахстане / Ю. В. Садовская. - Алматы : Ғалым, 2001. - 216 с.

15. Фалейчик Л. М. Использование ГИС-инструментария в анализе демографических показателей системы расселения Забайкальского края / Л. М. Фалейчик, К. В. Горина // Вестник Забайкальского государственного университета. - 2014. - № 3(106). - С. 45-56.

16. Boryas G. J. Economic Theory and International Migration / G. J. Boryas // International Migration Review. - 1989. - № 3. - P. 457-485.

\section{REFERENCES}

1. Belousov R. A. Obshchiy i spetsial'nyy menedzhment / R. A. Belousov, A. L. Gaponenko. - Moskva : Izdatel'stvo Rossiyskoy akademii gosudarstvennoy sluzhby, 2001. $-568 \mathrm{~s}$.

2. Gabdullina A. R. Gosudarstvennoye regulirovaniye migratsii sel'skikh zhiteley (problemy sotsial'no-ekonomicheskogo razvitiya sel'skikh territoriy Akmolinskoy oblasti) / A. R. Gabdullina // Ekonomika sel'skogo khozyaystva. Referativnyy zhurnal. - 2006. - № 1. - S. 161.

3. Demograficheskiy ezhegodnik Akmolinskoy oblasti 2007-2011 : Statisticheskiy sbornik. - Kokshetau : Upravleniye statistiki Akmolinskoy oblasti, 2012. - $119 \mathrm{~s}$.

4. Demograficheskiy ezhegodnik Akmolinskoy oblasti 2013 : Statisticheskiy sbornik. - Kokshetau : Upravleniye statistiki Akmolinskoy oblasti, 2014. - $119 \mathrm{~s}$.

5. Makkev I. YU.Migratsiya russkoyazychnogo naseleniya iz Kazakhstana / I. YU. Makkev // Sotsiologicheskiye issledovaniya. - 1999. - № 11. - S. 62-67. 
6. Matlin I. S. Modelirovaniye razmeshcheniya naseleniya / I. S. Matlin. - Moskva : Nauka, 1975. - 153 s.

7. Nesterov A. A. Obzor faktorov, opredelyayushchikh mezhregional'nuyu i regional'nuyu migratsiyu v Rossiyskuyu Federatsiyu / A. A. Nesterov // Rossiyskoye predprinimatel'stvo. - 2015. - № 5-2. - C. 183-187.

8. Pareto V. Kompendium po obshchey sotsiologii / V. Pareto; per. s ital. A. A. Zotova. - Moskva : Vysshaya shkola ekonomiki, 2008. - $511 \mathrm{~s}$.

9. Perspektivy rosta naseleniya $v$ Respublike Kazakhstan do 2021 goda / S. N. Tret'yakova [i dr.] // Vestnik Kazakhskogo natsional'nogo meditsinskogo universiteta. 2015. - № 1. - S. 494-496.

10. Plachinta I. G. Razrabotka priyema analiza vliyaniya ekonomicheskogo faktora na migratsiyu (na primere Akmolinskoy oblasti) / I. G. Plachinta // Nauka. Innovatsii. Tekhnologii. - 2018. - № 1. - S. 131-143.

11. Pritvorova T. P. Tendentsii demograficheskogo povedeniya naseleniya Akmolinskoy oblasti / T. P. Pritvorova,

\section{Плачинта Иван Георгиевич}

преподаватель кафедры географии, экологии, туризма Кокшетауского государственного университета им. Ш. Уалиханова, г. Кокшетау, E-mail: plachinta-ivan@mail.ru
M. SH. Takambayev // Vestnik Karagandinskogo gosudarstvennogo universiteta. - 2010. - № 2. - S. 21-27.

12. Rastvortseva S. N. Sotsial'no-ekonomicheskaya effektivnost' regional'nogo razvitiya / S. N. Rastvortseva. Moskva : Ekon-Inform, 2011. - 131 s.

13. Sadovskaya YU. V. Migratsiya v Kazakhstane na rubezhe XXI veka: osnovnyye tendentsii i perspektivy / YU. V. Sadovskaya. - Almaty : Falym, 2001. - S. 108-124.

14. Sadovskaya YU. V. Trudovaya migratsiya kak sredstvo adaptatsii k ekonomicheskomu krizisu v Kazakhstane / YU. V. Sadovskaya. - Almaty : Falym, 2001. - 216 s.

15. Faleychik L. M. Ispol'zovaniye GIS-instrumentariya $\mathrm{v}$ analize demograficheskikh pokazateley sistemy rasseleniya Zabaykal'skogo kraya / L. M. Faleychik, K. V. Gorina // Vestnik Zabaykal'skogo gosudarstvennogo universiteta. - 2014. - № 3(106). - S. 45-56.

16. Boryas G. J. Economic Theory and International Migration / G. J. Boryas // International Migration Review. - 1989. - № 3. - P. 457-485.

Plachinta Ivan Georgievitch

Lecturer of the Department of geography, ecology, tourism, Kokshetau State University named after Sh. Ualikhanov, E-mail: plachinta-ivan@ mail.ru 